\title{
Microporous covalent organic frameworks for sulfur hexafluoride capture and separation
}

\author{
Qiaobo Liao ${ }^{\text {a }}$, Haocheng $\mathrm{Xu}{ }^{\text {a }}$, Can Ke ${ }^{\text {a }}$, Yiying Zhang ${ }^{\text {a }}$, Qingwen Han ${ }^{\text {a, }}$ Yifan Zhang ${ }^{\text {a }}$, Yang Xu \\ a, Kai Xi *a \\ a School of Chemistry and Chemical Engineering, Nanjing University, Nanjing, Jiangsu 210023, P.R. China.
}

\begin{abstract}
Sulfur hexafluoride $\left(\mathrm{SF}_{6}\right)$ is the most potent greenhouse gas whose emission is in great need of reducing during the industrial processes. Here, a variety of covalent organic frameworks with varying topologies, surface areas, pore size distributions is designed and synthesized for systematically studying structure-property relationships of $\mathrm{COF}^{-b a s e d} \mathrm{SF}_{6}$ adsorbents. Surface area was found to be a prerequisite for achieving high $\mathrm{SF}_{6}$ uptakes, and small pore size at ca. $0.9 \mathrm{~nm}$ could effectively enhance the adsorbate-adsorbent interaction and hence the $\mathrm{SF}_{6} / \mathrm{N}_{2}$ selectivity. With a large specific surface area and a suitable pore size, RCOF-1 showed superior $\mathrm{SF}_{6}$ adsorption capacities up to $4.13 \mathrm{mmol} \mathrm{g} \mathrm{m}^{-1}$ and large $\mathrm{SF}_{6} / \mathrm{N}_{2}$ selectivity up to $125(273 \mathrm{~K}, 100 \mathrm{kPa})$, which can be considered one of the most high-performance porous materials for $\mathrm{SF}_{6}$ capture and separation. This work not only provides a series of high-performance $\mathrm{SF}_{6}$ adsorbents, but also broadens the horizon of applications of the emerging COFs, pointing out their development direction in the field of $\mathrm{SF}_{6}$ capture and separation.
\end{abstract}

Sulfur hexafluoride $\left(\mathrm{SF}_{6}\right)$, an important industrial gas, has been widely used in high-voltage electrical equipment, metal industry, electronic industry and, etc. ${ }^{1}$ Despite its excellent electrical properties, $\mathrm{SF}_{6}$ is also the most potent greenhouse gas with a global warming potential (GWP) 23,900 times larger than that of $\mathrm{CO}_{2},{ }^{2}$ and an ultralong atmospheric lifetime over 1000 years. ${ }^{3}$ In 2018, the $\mathrm{SF}_{6}$ emission was estimated to be 9000 tons per year, which was equivalent to 215 million tons of $\mathrm{CO}_{2} \cdot{ }^{1}$ Economic and efficient strategies are therefore highly desired to settle the problem. Benefiting from the low running costs and large energy savings, pressure swing adsorption is deemed as an outstanding candidate for solving the problems of greenhouse emissions. ${ }^{4,5}$ So, high efficient adsorbents should be a promising solution to realize the efficient greenhouse gas capture and sequestration. ${ }^{6}$

Covalent organic frameworks (COFs), a kind of emerging crystalline porous organic material, have gathered tremendous scientific interests in the last decade and exhibited potential applications such as gas sorption and separation, heterogeneous catalysis, sensors, energy storage, and drug delivery. ${ }^{-9}$ Benefiting from light weight, large porosity, regular channels, designable structure and high chemical and thermal stability, COFs would be an ideal candidate of $\mathrm{SF}_{6}$ adsorbents. Light weight and large porosity are fundamental features for high gas uptakes, while the crystalline structures provide a platform to precisely tailor the adsorption properties and give deep insight into the structure-property relationship. Furthermore, the strong covalent linkage endows COFs with superior chemical and thermal stabilities, which is a key feature for industrial gas adsorbents. Although a variety of porous materials including zeolites, ${ }^{10,11}$ porous polymer and organic cages, ${ }^{12,13}$ activated carbons, ${ }^{14,15}$ and metal organic frameworks (MOFs) ${ }^{16-}$ ${ }^{20}$ have been tried for $\mathrm{SF}_{6}$ adsorption and separation, studies on COFs in this application are still rare. Recently, our group reported that the COF modified with 4-(trifluoromethyl)phenyl groups via the Suzuki-Miyaura coupling showed enhanced $\mathrm{SF}_{6}$ uptake and $\mathrm{SF}_{6} / \mathrm{N}_{2}$ selectivity. ${ }^{21}$ Cao et al. have theoretically explored the selective adsorption in COFs and MOFs adopting the grand canonical Monte Carlo (GCMC) method..$^{22}$ However, in-depth experimental researches are greatly needed for better performances and a deeper understanding of structure-property relationships of COF-based $\mathrm{SF}_{6}$ adsorbents.

Herein, we designed and synthesized a series of COFs with different topologies, surface areas and pore sizes, ascertaining the influences of these factors on the $\mathrm{SF}_{6}$ adsorption. We have found that large surface areas and suitable micropores at ca. $0.9 \mathrm{~nm}$ greatly enhanced the performance of COF-based adsorbents. Especially, the RCOF-1 with a large specific surface area of $1139 \mathrm{~m}^{2} \mathrm{~g}^{-1}$ and pore size of $0.95 \mathrm{~nm}$ exhibited superior $\mathrm{SF}_{6}$ adsorption capacities of $4.13(273 \mathrm{~K}, 100 \mathrm{kPa})$ and $3.46 \mathrm{mmol} \mathrm{g}^{-1}(298 \mathrm{~K}, 100 \mathrm{kPa})$ and excellent selectivity of 125 at $273 \mathrm{~K}$ and 85 at $298 \mathrm{~K}$, ranking high among the state-of-the-art $\mathrm{SF}_{6}$ adsorbents, being one of the most outstanding porous materials for $\mathrm{SF}_{6}$ capture and separation. For the first time, we achieved an experimental and systematical study on the $\mathrm{SF}_{6}$ adsorption and separation performance of COFs.

Compared with the more popular hexagonal $(h c b)$ COFs, rhombus ( $s q l)$ COFs are prone to forming smaller pores, ${ }^{23}$ which play a pivotal role for high-performance gas adsorbents. $^{24}$ Therefore, we devised and prepared a family of microporous rhombus COFs using tetraphenylethylene (TPE) monomers including 4, 4', 4", 4"'-(1, 2-ethenediylidene)tetrakis-benzaldehyde (ETTB), 4, 4', 4", 4"'-(ethene-1, 1, 2, 2-tetrayl)-tetraaniline (ETTA), 4', 4"', 4"'"', 4"'"'"-(1, 2ethenediylidene)tetrakis[1, 1'-biphenyl]-4-carboxaldehyde (ETBC) and 4', 4"', 4"'", 4"'"'"-(ethene-1, 1, 2, 2tetrayl)tetrakis $\left(\left(\left[1,1^{\prime}\right.\right.\right.$-biphenyl $]$-4-amine $\left.)\right)$ (ETBA) (named 

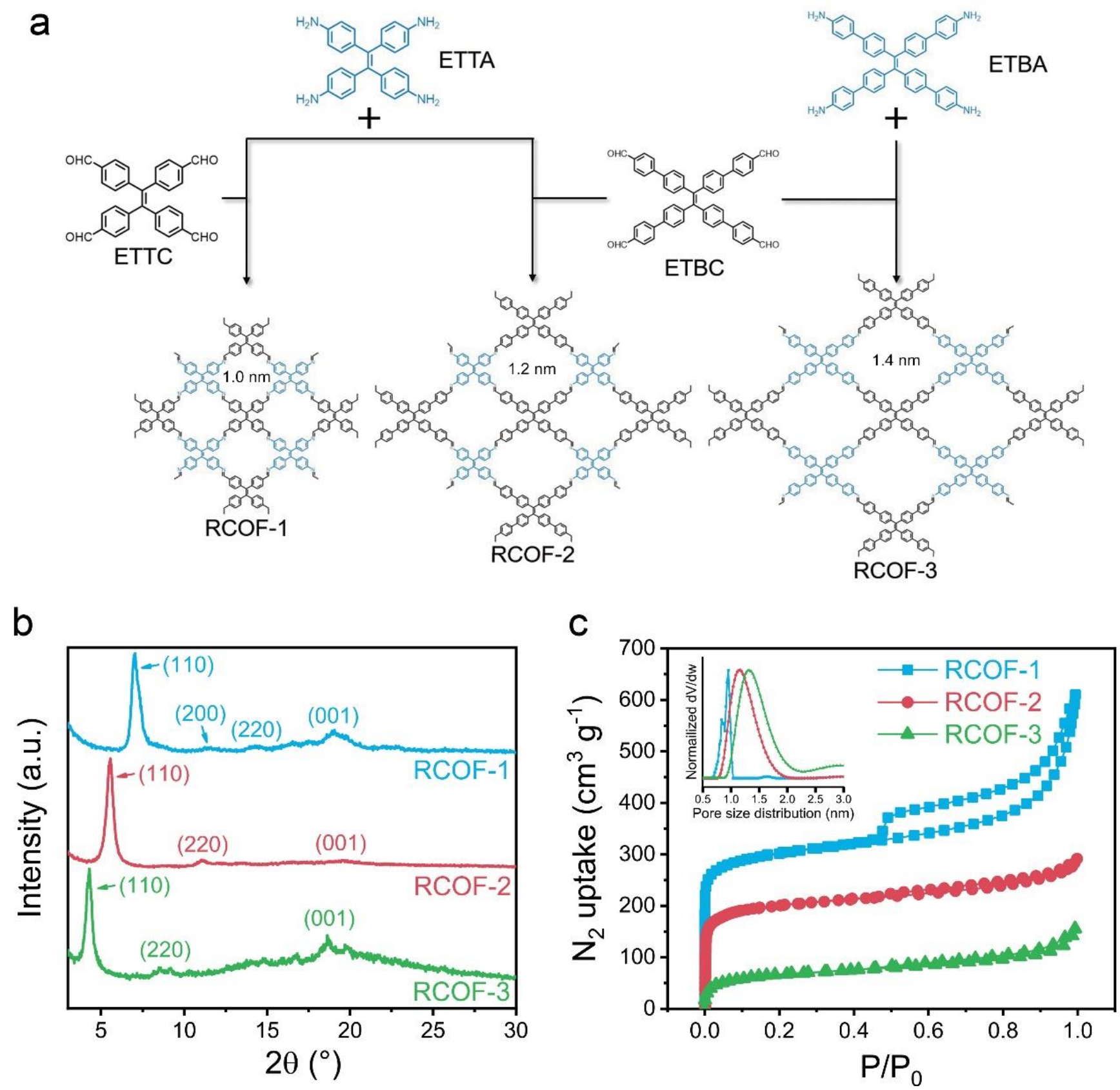

Figure 1. (a) Schematic representation of topological structures of RCOFs. (b) PXRD patterns and (c) $\mathrm{N}_{2}$ sorption isotherms measured at $77 \mathrm{~K}$ of RCOFs. Inset: pore size distributions of RCOFs.

RCOF-1, RCOF-2 and RCOF-3, respectively, "R" for rhombus, Fig. 1a). By simply changing the monomers, we were able to tailor the pore sizes of RCOFs easily and precisely. Note that the RCOF-1 and RCOF-2 were reported previously, ${ }^{25,26}$ while the RCOF-3 was not realized before. Despite their varying pore sizes, all RCOFs were chemically similar and possessed phenyl rings, carbon-carbon and carbon-nitrogen double bonds only, ruling out the interference of complicated chemical structures and offering an ideal platform for studying the influence of textural structures on $\mathrm{SF}_{6}$ capture and separation. Additionally, to further study the influence of the surface area, a series of
RCOF-1s with different porosities were synthesized by altering reaction conditions, and numbered from RCOF-1-2 to RCOF-1-5. As shown in Fig. S1, RCOF-1, RCOF-2 and RCOF-3 adopt flower-like, granular and coral-like morphologies, respectively, which are all loose and micronscale porous, being beneficial for efficient $\mathrm{SF}_{6}$ diffusion to micropores. Fourier transform infrared (FT-IR) spectra show the appearance of signals for $\mathrm{C}=\mathrm{N}$ stretching vibration $\left(1626 \mathrm{~cm}^{-1}\right.$ for RCOF-1, $1621 \mathrm{~cm}^{-1}$ for RCOF-2, $1623 \mathrm{~cm}^{-1}$ for RCOF-3, Fig. S2-S4), confirming the successful construction of imine bonds. Powder X-ray diffraction (PXRD) analysis was then conducted to investigate the crystalline 
a

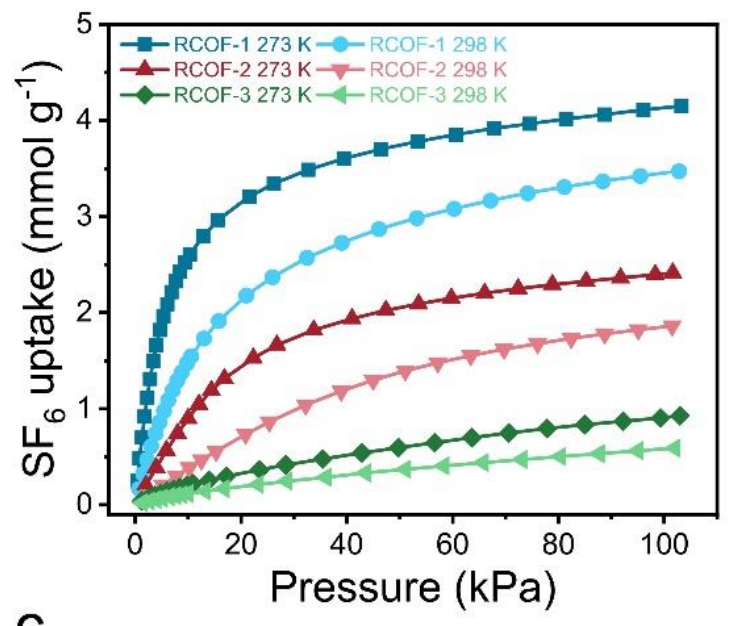

C

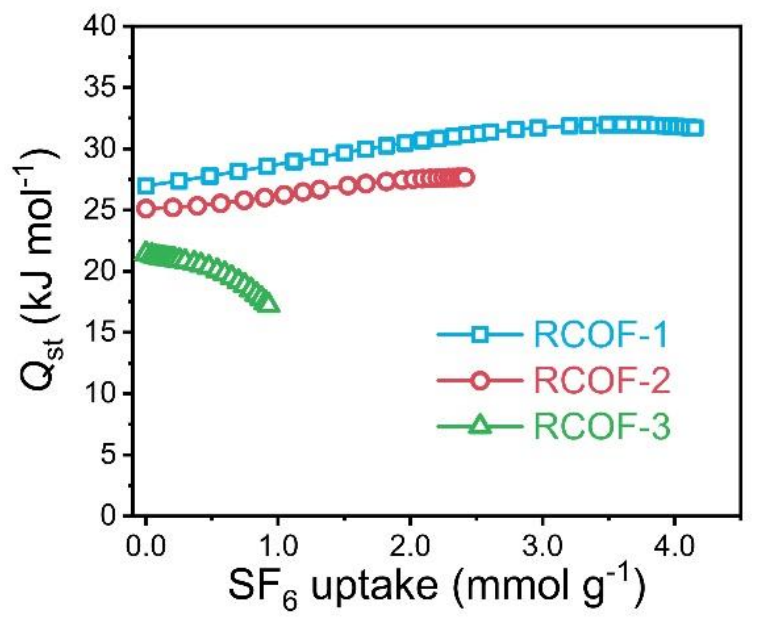

b
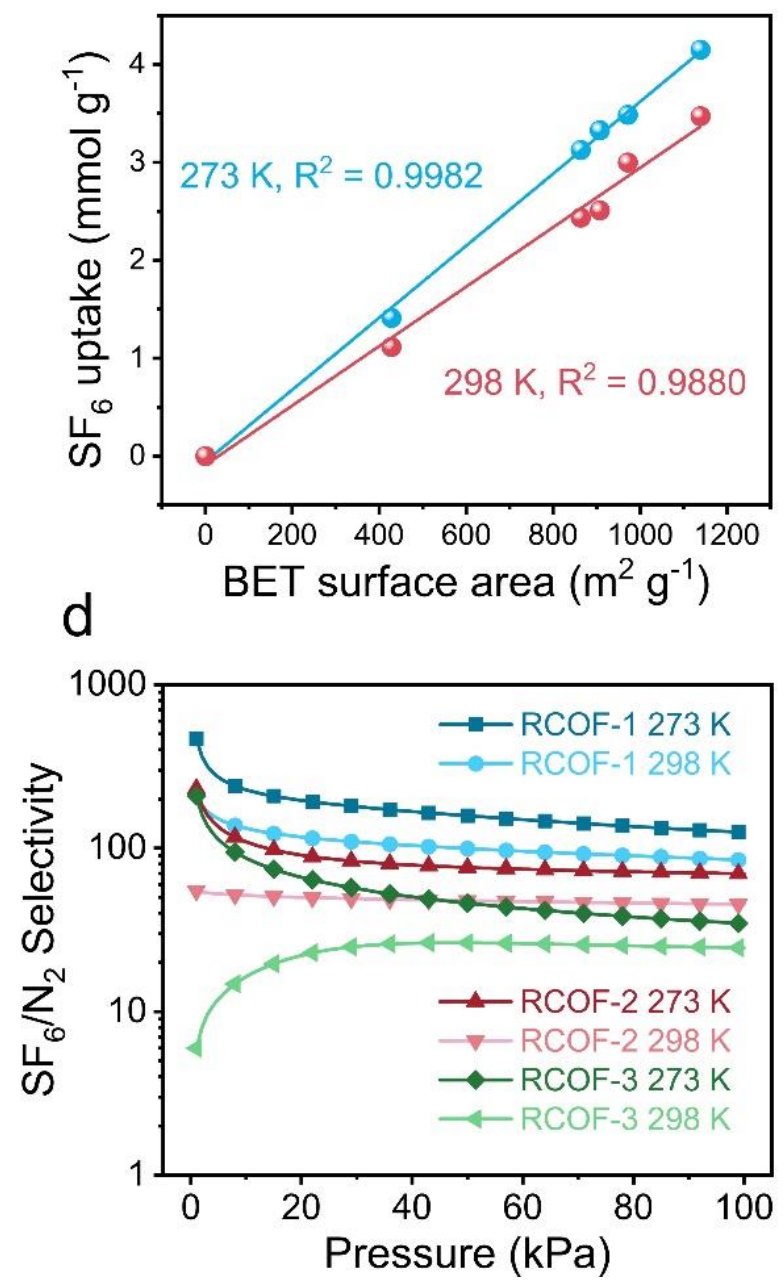

Figure 2. (a) $\mathrm{SF}_{6}$ adsorption isotherms of RCOFs at $273 \mathrm{~K}$ and $298 \mathrm{~K}$. (b) The linear correlations between $\mathrm{SF}_{6}$ uptakes at $273 \mathrm{~K}$ and $298 \mathrm{~K}, 100 \mathrm{kPa}$ and the BET surface areas of RCOF-1s. (c) Isosteric heat of adsorption, $Q_{\mathrm{st}}$ of RCOFs. (d) Calculated IAST SF $/ \mathrm{N}_{2}$ (10:90) selectivity of RCOFs at $273 \mathrm{~K}$ and $298 \mathrm{~K}$.

structures of RCOFs. Fig. $1 b$ demonstrates that all three RCOFs possess strong (110) peaks accompanied by several weaker peaks including (220) and (oo1) peaks in PXRD patterns, manifesting their high crystallinity. Remarkably, (110) peaks of RCOFs shifted to the left as the size of monomers increasing, evidencing the growing pore size distributions of RCOFs. The (oo1) peaks of RCOF-1, RCOF-2 and RCOF3 were centered at $18.6^{\circ}, 19.5^{\circ}$ and $18.6^{\circ}$, respectively, corresponding to similar layer-spacing of $0.476 \mathrm{~nm}, 0.455 \mathrm{~nm}$ and $0.476 \mathrm{~nm}$. Pawley refinement was employed to refined the geometry-optimized unit cells of RCOFs, giving good agreement factors $\left(\mathrm{R}_{\mathrm{wp}}\right)$ of $7.87 \%$ (RCOF-1), $7.37 \%$ (RCOF2) and $8.03 \%(\mathrm{RCOF}-3)$, which verified the simulated AAstacking structures (Fig. $\mathrm{S}_{5}-\mathrm{S}_{7}$ ). Besides, mean reflection peaks of RCOF-1s with different surface areas shifted barely regardless of their different intensity, demonstrating the crystalline structural similarity of these RCOF-1s (Fig. S8).

$\mathrm{N}_{2}$ sorption analysis at $77 \mathrm{~K}$ was exploited to determine the textural structures of RCOFs. All of the isotherms exhibited typical Type-I curves, evidencing the microporous nature of RCOFs (Fig. 1c). Based on these isotherms, Brunauer-Emmett-Teller (BET) surface areas of RCOF-1, RCOF-2 and RCOF-3 were calculated to be $1139 \mathrm{~m}^{2} \mathrm{~g}^{-1}, 763$ $\mathrm{m}^{2} \mathrm{~g}^{-1}$ and $242 \mathrm{~m}^{2} \mathrm{~g}^{-1}$, respectively. (Fig. 1c and S9-Si1). Pore volumes $\left(\mathrm{P} / \mathrm{P}_{\mathrm{o}}=0.99\right)$ were measured to be $0.944 \mathrm{~cm}^{3} \mathrm{~g}^{-1}$ for RCOF-1, $0.45^{1} \mathrm{~cm}^{3} \mathrm{~g}^{-1}$ for RCOF-2 and $0.240 \mathrm{~cm}^{3} \mathrm{~g}^{-1}$ for RCOF-3. On the other hand, pore sizes of RCOFs were also estimated by fitting the isotherms according to NLDFT, giving out values of $0.95 \mathrm{~nm}$ for RCOF-1, $1.15 \mathrm{~nm}$ for RCOF2 and $1.32 \mathrm{~nm}$ for RCOF-3, agreeing well with the PXRD results and affirming our design for precisely tailoring the pore size distribution of RCOFs with a constant interval (Fig. 1b, inset). Synthesized under different conditions, RCOF-1s possessed different BET surface areas ranging from $400-1100 \mathrm{~m}^{2} \mathrm{~g}^{-1}$ (984 $\mathrm{m}^{2} \mathrm{~g}^{-1}$ for RCOF-1-2, $945 \mathrm{~m}^{2} \mathrm{~g}^{-1}$ for RCOF-1-3, $864 \mathrm{~m}^{2} \mathrm{~g}^{-1}$ for RCOF-1- 4 and $428 \mathrm{~m}^{2} \mathrm{~g}^{-1}$ for RCOF1-5, Fig. S12-S15), while their pore sizes at around o.8-0.9 $\mathrm{nm}$ were well preserved (Fig. S16).

$\mathrm{SF}_{6}$ adsorption analysis at $273 \mathrm{~K}$ and $298 \mathrm{~K}$ was then employed to evaluate the performance of RCOFs (Fig. 2a). 
Table 1. Textural properties and performance for $\mathrm{SF}_{6}$ adsorption and separation of RCOFs.

\begin{tabular}{|c|c|c|c|c|c|c|c|c|c|c|c|c|c|c|}
\hline \multirow{2}{*}{ Sample } & \multirow{2}{*}{$\begin{array}{c}S_{\mathrm{BET}} \\
\left(\mathrm{m}^{2} \mathrm{~g}^{-}\right. \\
\left.{ }^{1}\right)\end{array}$} & \multirow{2}{*}{$\begin{array}{c}V_{\text {total }} \\
\left(\mathrm{cm}^{3} \mathrm{~g}^{-}\right. \\
1)^{\mathrm{a}}\end{array}$} & \multirow{2}{*}{$\begin{array}{c}\text { PSD } \\
\left(\begin{array}{c}\mathrm{nm}) \\
\mathrm{b}\end{array}\right.\end{array}$} & \multicolumn{2}{|c|}{$\begin{array}{c}N_{\mathrm{SF}_{6}, 100 \mathrm{kPa}}(\mathrm{mmol} \\
\left.\mathrm{g}^{-1}\right)\end{array}$} & \multicolumn{2}{|c|}{$\begin{array}{c}N_{\mathrm{SF}_{6}, \text { } 10 \mathrm{kPa}}\left(\mathrm{mmol} \mathrm{g}^{-}\right. \\
\text {1) }\end{array}$} & \multicolumn{2}{|c|}{$\begin{array}{c}N_{\mathrm{SF}_{6}, 10 \mathrm{kPa}} / N_{\mathrm{SF}_{6}}, \\
100 \mathrm{kPa}\end{array}$} & \multicolumn{2}{|c|}{$\begin{array}{c}K_{\mathrm{H}}\left(\mathrm{mmol} \mathrm{g}^{-1}\right. \\
\text { bar })\end{array}$} & \multirow{2}{*}{$\begin{array}{l}Q_{\text {st }}(\mathrm{kJ} \\
\left.\mathrm{mol}^{-1}\right)^{\mathrm{c}}\end{array}$} & \multicolumn{2}{|c|}{$S_{\mathrm{SF}_{6} / \mathrm{N}_{2}}$} \\
\hline & & & & $273 \mathrm{~K}$ & $298 \mathrm{~K}$ & $273 \mathrm{~K}$ & $298 \mathrm{~K}$ & $273 \mathrm{~K}$ & $298 \mathrm{~K}$ & $\begin{array}{c}273 \\
\mathrm{~K}\end{array}$ & $\begin{array}{c}298 \\
K\end{array}$ & & $\begin{array}{c}273 \\
\mathrm{~K}\end{array}$ & $\begin{array}{c}298 \\
K\end{array}$ \\
\hline RCOF-1 & 1139 & 0.944 & 0.95 & 4.13 & 3.46 & 2.59 & 1.50 & 0.63 & 0.43 & 64.7 & 24.0 & 27.0 & 125 & 85 \\
\hline $\begin{array}{c}\text { RCOF- } \\
1-2\end{array}$ & 984 & 0.603 & 0.89 & 3.47 & 2.97 & 2.29 & 1.29 & 0.66 & 0.43 & $77 \cdot 5$ & 22.2 & 33.2 & 112 & 78 \\
\hline $\begin{array}{c}\text { RCOF- } \\
1-3\end{array}$ & 945 & 0.771 & 0.83 & $3 \cdot 30$ & 2.49 & 2.01 & 1.08 & 0.61 & 0.43 & $57 \cdot 4$ & 18.5 & $27 \cdot 7$ & 113 & 83 \\
\hline $\begin{array}{c}\text { RCOF- } \\
1-4\end{array}$ & 864 & 0.612 & 0.86 & 3.11 & 2.42 & 1.93 & 1.13 & 0.62 & 0.47 & $74 \cdot 4$ & 22.2 & 29.2 & 112 & 87 \\
\hline $\begin{array}{c}\text { RCOF- } \\
1-5\end{array}$ & 428 & 0.368 & 0.79 & 1.41 & 1.11 & 0.816 & 0.496 & 0.58 & 0.45 & 46.1 & 12.6 & 30.0 & 72 & 52 \\
\hline RCOF-2 & 763 & 0.451 & 1.15 & 2.41 & 1.86 & 0.902 & 0.380 & 0.37 & 0.21 & 10.5 & 4.10 & 25.1 & 70 & 45 \\
\hline $\mathrm{RCOF}_{-3}$ & 242 & 0.240 & 1.32 & 0.914 & 0.581 & 0.203 & 0.116 & 0.22 & 0.20 & 3.13 & 1.73 & 21.4 & 34 & 25 \\
\hline
\end{tabular}

Among these three COFs, RCOF-1 showed highest $\mathrm{SF}_{6}$ uptakes at $100 \mathrm{kPa}\left(4.13 \mathrm{mmol} \mathrm{g}^{-1}, 273 \mathrm{~K} ; 3.46 \mathrm{mmol} \mathrm{g}^{-1}, 298 \mathrm{~K}\right)$, while RCOF-2 and RCOF-3 performed much poorer (RCOF-2: $2.41 \mathrm{mmol} \mathrm{g}^{-1}, 273 \mathrm{~K} ; 1.86 \mathrm{mmol} \mathrm{g}^{-1}$, $298 \mathrm{~K}$; RCOF3: $\left.0.914 \mathrm{mmol} \mathrm{g}^{-1}, 273 \mathrm{~K} ; 0.581 \mathrm{mmol} \mathrm{g}^{-1}, 298 \mathrm{~K}\right)$. It seems that the $\mathrm{SF}_{6}$ uptakes were mainly attributed to the surface areas ( $\mathrm{RCOF}-1>\mathrm{RCOF}-2>\mathrm{RCOF}-3)$, driving us to evaluate the adsorption performance of RCOF-1s with varying BET surface areas. Obviously, the linear fitting showed clear correlations between $\mathrm{SF}_{6}$ uptakes and BET surface areas of RCOF-1s with excellent R-squares at both temperatures (Fig. 2b), hinting that surface area was a prerequisite for achieving high $\mathrm{SF}_{6}$ capacity in the atmosphere $(\sim 100 \mathrm{kPa})$. Apart from the surface area, pore size distribution has been demonstrated to affect the $\mathrm{SF}_{6}$ uptakes. As shown in Fig 2a, the $\mathrm{SF}_{6}$ isotherms at the low-pressure region of RCOF-1 are much steeper than those of RCOF-2 and $\mathrm{RCOF}-3$, suggesting its stronger affinity towards $\mathrm{SF}_{6}$ molecules. To quantify the curvature of these isotherms, the ratio of $\mathrm{SF}_{6}$ uptakes at $10 \mathrm{kPa}$ and $100 \mathrm{kPa}$ were calculated (Table 1 ). For both temperatures, the order of ratios followed the order of pore sizes, i.e., the COF with smaller pore sizes showed a steeper isotherm. Furthermore, we derived Henry's constant from the $\mathrm{SF}_{6}$ isotherms, which has been considered as an indicator of adsorbent-adsorbate interaction and adsorption selectivity. ${ }^{27}$ As listed in Table 1 , Henry's constant of RCOF-1 far outperforms those of RCOF-2 and RCOF-3, which is in congruence with the curvature of the isotherms. It is noteworthy that Henry's constant of RCOF-1-5 was much smaller than those of other RCOF-1s, which might be stemmed from its lower crystallinity and thus fewer adsorption sites for $\mathrm{SF}_{6}$ molecules. To get a deeper insight into the strength of interaction between the adsorbent and adsorbate, we acquired the isosteric heat of adsorption $\left(Q_{\mathrm{st}}\right)$ using $\mathrm{SF}_{6}$ isotherms measured at $273 \mathrm{~K}$ and $298 \mathrm{~K}$ based on the Clausius-Clapeyron equation (Fig. 1c). Clearly, RCOF-1 exhibited the largest $Q_{\text {st }}$ value at zero coverage $\left(27.0 \mathrm{~kJ} \mathrm{~mol}^{-}\right.$ ${ }^{1}$ for RCOF-1, 24.4 kJ mol ${ }^{-1}$ for RCOF-2, $21.4 \mathrm{~kJ} \mathrm{~mol}^{-1}$ for
RCOF-3), which coincided with the above outcomes. Even though the crystallinity and porosity of RCOF-1-5 were far smaller than RCOF-2, the curvature, Henry's constant and $Q_{\text {st }}$ of RCOF-1-5 far exceeded those of RCOF-2. The results undoubtedly showed that the $\mathrm{SF}_{6}$ affinity of COF was mainly governed by the pore size distribution, and RCOF1 performed the best due to its optimal pore size.

Ideal adsorbed solution theory (IAST) is a simple and efficient method to evaluate the selectivity of adsorbents for two-component gas mixture, based solely on the pure-gas isotherms at equivalent temperature. ${ }^{28} \mathrm{~N}_{2}$ sorption isotherms of RCOFs were hence measured at $273 \mathrm{~K}$ and $298 \mathrm{~K}$, respectively, for calculating $\mathrm{SF}_{6} / \mathrm{N}_{2}$ selectivity. The industrially relevant $\mathrm{SF}_{6} / \mathrm{N}_{2}$ composition $\mathrm{SF}_{6}: \mathrm{N}_{2}=10: 90$ was considered in this work. ${ }^{17}$ At $100 \mathrm{kPa}, \mathrm{RCOF}-1$ outstripped RCOF-2 and RCOF-3 at all tested temperatures, attributing to its stronger interaction to the guest molecules (Table 1 ). Additionally, all RCOF-1s except RCOF-1-5 exhibited similar selectivity despite different surface areas, which evidences that pore size was the root cause determining the selectivity rather than the porosity. Low crystallinity and disorder structures of RCOF-1-5 might compromise its separation property, which was in line with the discussion on Henry's constants. Still, the performance of RCOF-1-5 was better than that of RCOF-2 owing to its better pore size.

Additionally, the stability of the $\mathrm{SF}_{6}$ adsorbents is another critical factor for practical uses. For this purpose, RCOF-1 was re-activated by heating at $120{ }^{\circ} \mathrm{C}$ under vacuum for 2 hours, and subjected to the repeated $\mathrm{SF}_{6}$ adsorption experiment performed at $298 \mathrm{~K}$. As shown in Fig. 3, the performance of RCOF-1 exhibited no change in 6 cycles. The morphology of the used sample changed negligibly as revealed by SEM (Fig S17). The FT-IR spectrum (Fig. S18) and the PXRD pattern (Fig. S19) of the recycled RCOF-1 demonstrate that the chemical and crystalline structures are well preserved even after the 6th cycle, suggesting the 
Table 2 Textural properties and performance for $\mathrm{SF}_{6}$ adsorption and separation of COFs studied in this work.

\begin{tabular}{cccccccc}
\hline \multirow{2}{*}{ Sample } & \multirow{2}{*}{$S_{\mathrm{BET}}\left(\mathrm{m}^{2} \mathrm{~g}^{-1}\right)$} & \multirow{2}{*}{$V_{\text {total }}\left(\mathrm{cm}^{3} \mathrm{~g}^{-1}\right)^{\mathrm{a}}$} & \multirow{2}{*}{$\mathrm{PSD}(\mathrm{nm})^{\mathrm{b}}$} & & $N_{\mathrm{SF}_{6}, 100 \mathrm{kPa}}\left(\mathrm{mmol} \mathrm{g}^{-1}\right)$ & \multicolumn{2}{c}{$S_{\mathrm{SF}_{6} / \mathrm{N}_{2}}$} \\
\cline { 5 - 8 } & & & & $273 \mathrm{~K}$ & $298 \mathrm{~K}$ & $273 \mathrm{~K}$ & $298 \mathrm{~K}$ \\
\hline RCOF-1 & 1139 & 0.944 & 0.95 & 4.13 & 3.46 & 125 & 85 \\
COF & 390 & 0.739 & 0.75 & 0.84 & 0.63 & 52 & 36 \\
COF-300 & 1106 & 0.680 & $0.94,2.55^{\mathrm{d}}$ & 4.03 & 3.09 & 70 & 51 \\
ACOF-1 & 831 & 0.497 & 1.09 & 2.57 & 2.33 & 67 & 54 \\
FCOF-1 & 1885 & 1.043 & $3.5^{\mathrm{e}}$ & 2.21 & 1.08 & 22 & 14 \\
KFCOF-1 & 744 & 0.497 & $1.36,3.5^{\mathrm{e}}$ & 1.58 & 0.99 & 42 & 33 \\
\hline
\end{tabular}

a Total pore volume calculated at $\mathrm{P} / \mathrm{P}_{\mathrm{o}}=0.99$.

b Pore size distribution determined by NLDFT method with heterogeneous surface model.

${ }^{\mathrm{c}}$ Heat of adsorption at zero coverage.

${ }^{\mathrm{d}}$ Mesopore, may be originated from the defects in the crystal

e Pore size distribution determined by NLDFT method with cylindrical pore model.

excellent stability of RCOF-1 and a great potential for industrial applications, which can be contributed to the strong covalent linkages. ${ }^{29}$

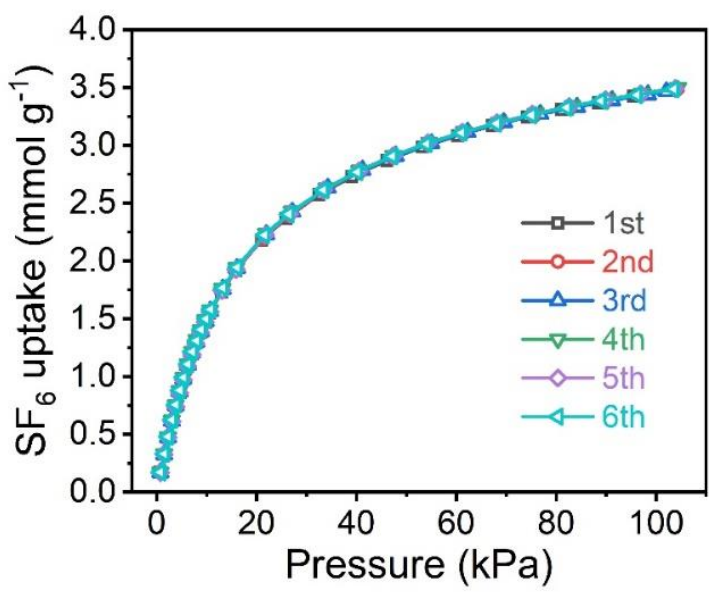

Figure $3 . \mathrm{SF}_{6}$ adsorption isotherms at $298 \mathrm{~K}$ of recycled RCOF1.

Topology is a fundamental characteristic of COFs, determining their crystalline structures and affecting their properties. To explore the influence of topology on $\mathrm{SF}_{6}$ capture, we selected several microporous covalent organic frameworks including Tp-Mela COF, ${ }^{30,31} \mathrm{ACOF}^{-3^{2}}$ and COF300,33 which adopted the most representative topologies, and compared them with RCOF-1 (Fig. 4a). Tp-Mela COF and ACOF-1 are two-dimensional COFs formed into a typical hexagonal $(h c b)$ topology with AA stacking mode, ${ }^{32}$ while COF-3oo represents three-dimensional COFs with multifold interpenetrating dia topology. 33 Despite their different topologies, selected COFs are all microporous with main pore size distributions below $1.2 \mathrm{~nm}$. Besides, mesoporous and heteroporous COFs were also prepared for comparison. For the reason that unmodified imine-linked 2D COFs with large mesopores are thermally unstable to some extent, ${ }^{34}$ we chose the robust and high-crystalline fluorinated FCOF-1 with hex topology and KFCOF-1 with kagome $(\mathrm{kgm})$ topology in this work. ${ }^{35,36}$ All the COFs were synthesized with solvothermal condensations.

SEM images of COFs show different microscale morphologies including flower-like (Tp-Mela COF, KFCOF-1), granular (ACOF-1, COF-30o) and sponge-like (FCOF-1) (Fig. S20-S21). FT-IR (Fig. S22-S26), PXRD patterns and structural simulations (Fig. S27-S31) of these COFs were consistent with the reported results, affirming their chemical and crystalline structures. ${ }^{32,33}$ All 2D COFs studied here adopted AA stacking mode. It is worth mentioning that aqueous acetic acid solution was used as the catalyst to synthesize COF-30o, leading to a contracted $3 \mathrm{D}$ structure with a smaller pore size $(<1 \mathrm{~nm})$ rather than the porous one $(\sim 1.3 \mathrm{~nm}) .37,38$ Thermal gravimetric analysis (TGA) revealed that all COFs were thermally stable with degradation temperatures ranging from $335^{\circ} \mathrm{C}$ to $546{ }^{\circ} \mathrm{C}$, empowering them to withstand the temperatures in the $\mathrm{SF}_{6}$ sorption process (Fig. S32-S37). $\mathrm{N}_{2}$ sorption analysis revealed that BET surface areas of microporous COFs were around $1000 \mathrm{~m}^{2} \mathrm{~g}^{-1}$, except for Tp-Mela COF (Table 2, Fig. S38-S4o). The mesoporous FCOF-1 possessed the highest BET surface area of $1885 \mathrm{~m}^{2} \mathrm{~g}^{-1}$ (Fig. S41), while that of its sibling KFCOF-1 was less than $1000 \mathrm{~m}^{2} \mathrm{~g}^{-1}$ (Fig. S42). Nonlinear density functional theory (NLDFT) calculation with heterogeneous surface model confirmed the microporous nature of Tp-Mela COF, COF-30o, ACOF-1 and KFCOF-1 (Table 2, Fig $\mathrm{S}_{43}$ ). Despite of the small discrepancies between the experimental and predicted results which might stem from the slightly serrated stacking structures and the limitations of the estimation method, 15,32 the order of the pore sizes conformed to our design strictly. It should be noted that except for the micropore of $0.94 \mathrm{~nm}, \mathrm{COF}-300$ exhibited another board pore size distribution centered at 2.55 $\mathrm{nm}$, which might arise from the defects in the crystal. On account of the large underestimation of heterogeneous surface model for mesopores (Fig. S44), the cylindrical pore model was applied to evaluate the mesoporous structure of FCOF-1 and KFCOF-1, giving pore size distributions at $3.5 \mathrm{~nm}$, much closer to the predicted values (Fig $\mathrm{S}_{45}$ ).

For microporous COFs, we found that $\mathrm{SF}_{6}$ uptakes at both temperatures positively correlated to the BET surface 

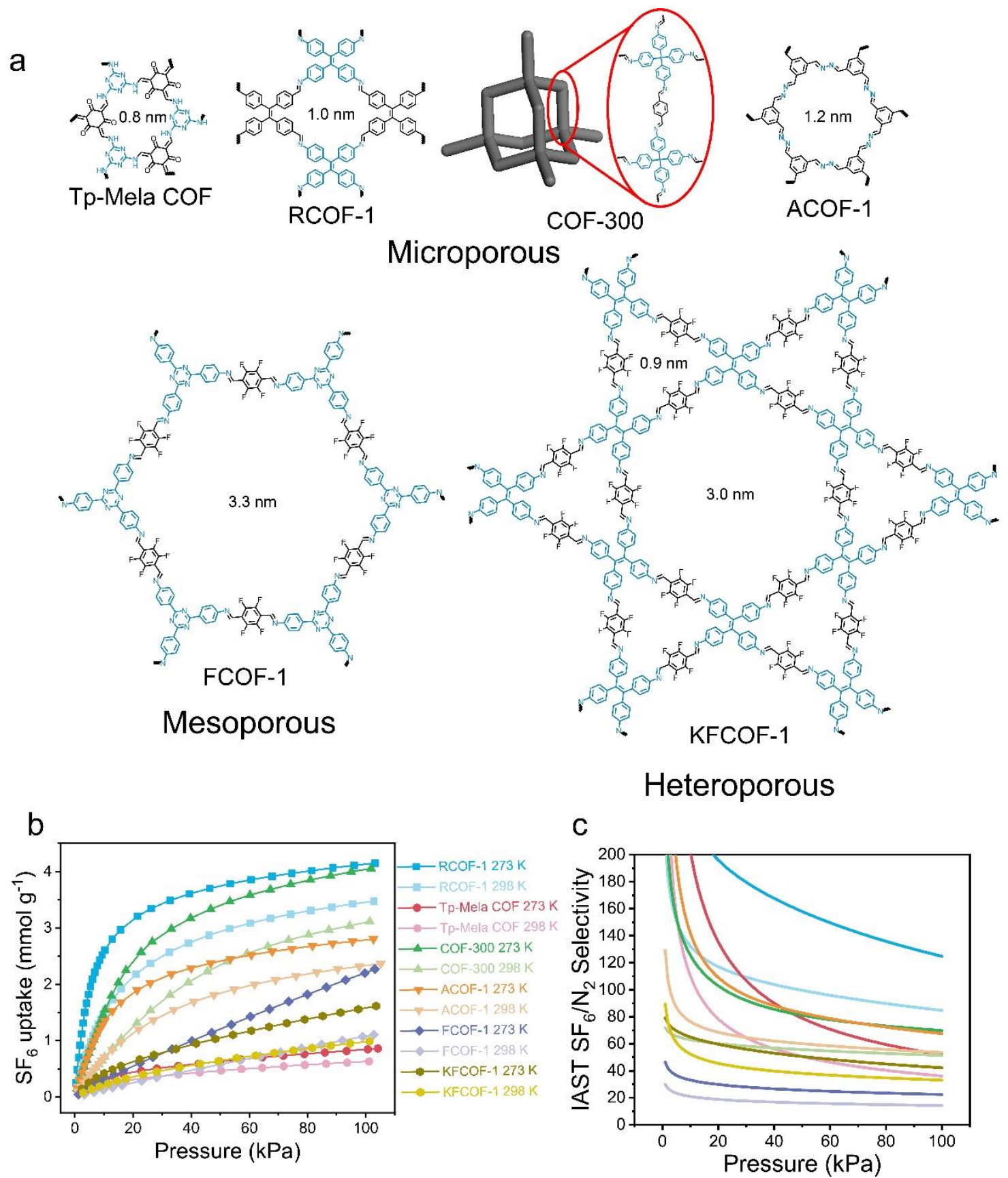

Figure 4. (a) Schematic representation of topological structures of COFs. (b) SF 6 adsorption isotherms and (c) calculated IAST $\mathrm{SF}_{6} / \mathrm{N}_{2}$ (10:90) selectivities at $273 \mathrm{~K}$ and $298 \mathrm{~K}$.

areas, showing well linear correlations (Table 2, Fig.4b and Fig. S46). With the largest surface area among microporous COFs (1139 $\left.\mathrm{m}^{2} \mathrm{~g}^{-1}\right)$, RCOF-1 displayed the highest $\mathrm{SF}_{6}$ uptakes at $100 \mathrm{kPa}$. However, the surface area was not so effective in the field of mesoporous COFs. In spite of its ultralarge surface area, the $\mathrm{SF}_{6}$ adsorption performance of FCOF-1 was far inferior to RCOF-1, hinting that mesopores counted against the $\mathrm{SF}_{6}$ uptake. More evidence was provided by comparing FCOF-1 with KFCOF-1, the heteroporous fluorinated $\mathrm{COF}$ embodying both micropores and mesopores. Even though the surface area of KFCOF-1 was only $40 \%$ of that of FCOF-1, their $\mathrm{SF}_{6}$ capacities were comparable, especially at $298 \mathrm{~K}$, further manifesting the importance of micropores for enhancing $\mathrm{SF}_{6}$ uptakes at 100 $\mathrm{kPa}$.

In the field of IAST SF $/ \mathrm{N}_{2}$ (10:90) selectivity (Table 2 and Fig. 4c), RCOF-1 performed the best among microporous COFs, suggesting its pore size $(0.95 \mathrm{~nm})$ might be the optimal value for enhancing $\mathrm{SF}_{6} / \mathrm{N}_{2}$ selectivity. For Tp-Mela COF with a smaller pore size distribution $(0.75 \mathrm{~nm})$ and ACOF-1 with a larger pore size distribution $(1.09 \mathrm{~nm})$, the performances were largely impaired. On the other hand, the inclusion of mesopores would also significantly reduce 

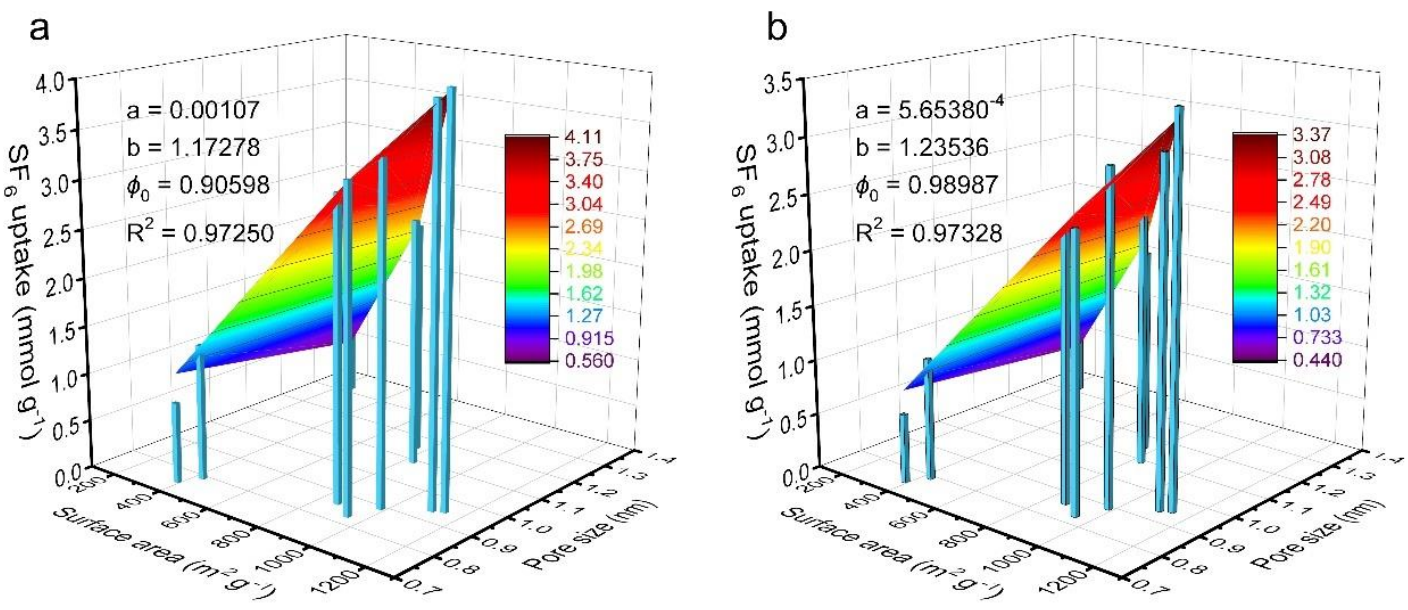

Figure 5. Fitting results of the relationship of between the surface area, the pore size and the SF 6 uptakes of microporous COFs at (a) $273 \mathrm{~K}$ and (b) $298 \mathrm{~K}$.

the selectivity as shown in the case of COF-30o. Although their pore size and surface area were comparable, COF-30o was far transcended by RCOF-1 in terms of $\mathrm{SF}_{6} / \mathrm{N}_{2}$ selectivity, which could be ascribed to the irregular mesopores in COF-30o. Similarly, the selectivities of heteroporous KFCOF-1 were nearly twice those of FCOF-1 with only mesopores. The above results demonstrate that the topology of COFs was not the direct factor governing the performance, while the surface area and pore size distribution played the dominant roles.

To quantify the contribution of the surface area and the pore size, we fitted the relationship between these factors and $\mathrm{SF}_{6}$ uptakes of all microporous COFs (pore size $<1.3$ $\mathrm{nm})$ studied in this work with the following equation (1):

$$
N=\mathrm{a} S^{b} e^{-\left(\phi-\phi_{0}\right)^{2}}
$$

Here, $N$ is the $\mathrm{SF}_{6}$ uptake at $100 \mathrm{kPa}$; and $\phi$ are the BET surface area and the pore size of COFs, respectively; $a, b$, $\phi_{0}$ are fitting coefficients. Considering the approximately linear correlation between the surface area and $\mathrm{SF}_{6}$ uptakes, we chose a power function to describe the contribution of surface area. As for the pore size, a negative exponential function $e^{-\left(\phi-\phi_{0}\right)^{2}}$ was applied for the reason that an optimal value $\phi_{0}$ might exist to maximize the uptake. As shown in Fig. 5, the data collected in $273 \mathrm{~K}$ and $298 \mathrm{~K}$ fitted well with the equation. Both $\mathrm{b}$ coefficients are close to unity as expected, proving the positive relationship between the surface area and the $\mathrm{SF}_{6}$ uptake. For $273 \mathrm{~K}$ and $298 \mathrm{~K}$, the optimal pore sizes $\phi_{0}$ were fitted to be 0.90598 $\mathrm{nm}$ and $0.98987 \mathrm{~nm}$, respectively, which were close to the theoretically predicted value $(\sim 0.9 \mathrm{~nm})$ that was ideal for improving the Van der Waals interaction between the pore wall and the $\mathrm{SF}_{6}$ molecules. ${ }^{22}$ Therefore, we could draw the solid conclusion that surface area enhanced the $\mathrm{SF}_{6}$ uptake, while the suitable pore size of around $0.9 \mathrm{~nm}$ accelerated the adsorption process as the pressure increasing and made the $\mathrm{SF}_{6}$ uptake reaching to the maximum quickly.

Furthermore, the performance of COFs for $\mathrm{SF}_{6}$ adsorption and separation were comparable or even better than state-of-the-art $\mathrm{SF}_{6}$ adsorbents including MOFs, activated carbons, porous organic cages and polymers. As shown in Fig. 6, some MOFs can achieve extremely high $\mathrm{SF}_{6}$ selectivities $^{18,20}$ for their high crystallinity and regular micropores. However, heavy metal atoms embedded in MOFs would largely reduce the surface area, resulting in low capacity. On the contrary, it was much easier for porous carbon materials to record high $\mathrm{SF}_{6}$ uptakes because of the excellent porosities, while their $\mathrm{SF}_{6} / \mathrm{N}_{2}$ selectivities were limited due to the difficulties of precise pore size controlling. Combining high crystallinity and large porosity, COFs broke the old rules of trade-off between capacity and selectivity, paving a new way to higher performance. Featuring large $\mathrm{SF}_{6}$ uptakes and $\mathrm{SF}_{6} / \mathrm{N}_{2}$ selectivity, RCOF-1 can be considered as one of the best $\mathrm{SF}_{6}$ adsorbents. It is reasonable that better materials for $\mathrm{SF}_{6}$ capture and separation would bloom with further efforts to functionalize COFs, develop efficient synthetic methods and optimize the work-up procedures.

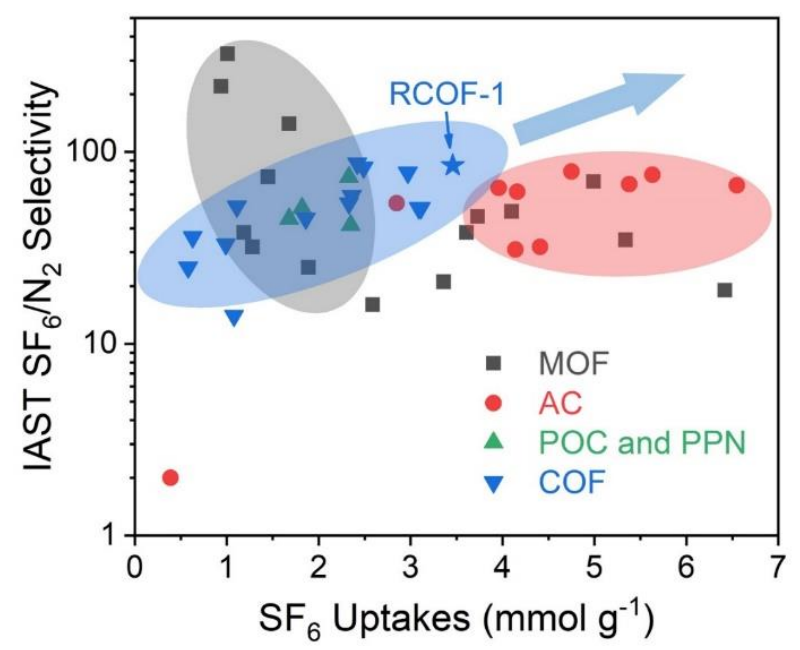

Figure 6. Comparison of $\mathrm{SF}_{6}$ adsorption and separation performance at $298 \mathrm{~K}$ between $\mathrm{COF}$ studied in this work and other reported state-of-the-art $\mathrm{SF}_{6}$ adsorbents. ${ }^{12-20,} 38-4 \mathrm{O}$ 
To sum up, several COFs with different topologies, surface areas and pore sizes were systematically designed and synthesized to study the effects of these factors on $\mathrm{SF}_{6}$ sorption and $\mathrm{SF}_{6} / \mathrm{N}_{2}$ separation. We have discovered that: 1) Surface area is the major contributor to $\mathrm{SF}_{6}$ uptakes especially under high pressure for microporous COFs; 2) Pore size distribution determined the $\mathrm{SF}_{6}$ affinity of COFs and thus the $\mathrm{SF}_{6} / \mathrm{N}_{2}$ selectivity. Pore size at ca. $0.9 \mathrm{~nm}$ might be the optimal value, verifying the theoretically predicted results. 3) Topology of COFs exerts influences on the performance indirectly by modulating their surface areas and pore size distributions. With a large BET surface area of $1139 \mathrm{~m}^{2} \mathrm{~g}^{-1}$ and a suitable pore size, RCOF-1 exhibited outstanding performance on $\mathrm{SF}_{6}$ capture and separation, ranking high among the state-of-the-art $\mathrm{SF}_{6}$ adsorbents. This work not only developed a series of high-performance $\mathrm{SF}_{6}$ adsorbents, but also paves an avenue for emerging $\mathrm{COF}$ materials toward $\mathrm{SF}_{6}$ capture and separation

\section{ASSOCIATED CONTENT}

Supporting Information. This material is available free of charge via the Internet at http://pubs.acs.org.

\section{AUTHOR INFORMATION}

\section{Corresponding Author}

*xikai@nju.edu.cn

\section{Author Contributions}

The manuscript was written through contributions of all authors.

\section{Notes}

The authors declare no competing financial interest.

\section{ACKNOWLEDGMENT}

This work was supported by Ministry of Science and Technology of China (2017YFAo70050o), and Postgraduate Research \& Practice Innovation Program of Jiangsu Province (No. KYCX21_oo34). The authors appreciate helpful discussions with Prof. Xiaoliang Wang (Nanjing University). The authors also would like to thank Shiyanjia Lab (www.shiyanjia.com) for supporting the TGA measurement.

\section{REFERENCES}

(1) Henne, S.; Reimann, S.; Vollmer, M. K.; Mühle, J.; Weiss, R. F.; Salameh, P. K.; Harth, C. M.; Manning, A. J.; Krummel, P. B.; Fraser, P. J.; et al. Atmos. Chem. Phys. 2020, 20, 7271-7290.

(2) Houghton, E. Climate Change 1995: The Science of Climate Change: Contribution of Working Group I to the Second Assessment Report of the Intergovernmental Panel on Climate Change; Cambridge University Press, 1996; Vol. 2.

(3) Kovács, T.; Feng, W.; Totterdill, A.; Plane, J.; Dhomse, S.; Gómez-Martin, J. C.; Stiller, G. P.; Haenel, F. J.; Smith, C.; Forster, P. M.; et al. Atmos. Chem. Phys. 2017, 17, 883-898.

(4) Chuah, C. Y.; Lee, Y.; Bae, T. H. Chem. Eng. J. 2021, 404, 126577 .

(5) Sumida, K.; Rogow, D. L.; Mason, J. A.; McDonald, T. M.; Bloch, E. D.; Herm, Z. R.; Bae, T.-H.; Long, J. R. Chem. Rev. 2012, 112, 724-781.
(6) Yang, R. T. Adsorbents: Fundamentals and Applications; John Wiley \& Sons, 2003.

(7) Li, X.; Yang, C.; Sun, B.; Cai, S.; Chen, Z.; Lv, Y.; Zhang, J.; Liu, Y. J. Mater. Chem. A 2020, 8, 16045-1606o.

(8) Liang, R. R.; Jiang, S. Y.; Ru-Han, A.; Zhao, X. Chem.

Soc. Rev. 2020, 49, 3920-3951.

(9) Sun, T.; Xie, J.; Guo, W.; Li, D.-S.; Zhang, Q. Adv.

Energy Mater. 2020, 10, 1904199.

(10) Cho, W. S.; Lee, K. H.; Chang, H. J.; Huh, W.; Kwon, H. H. Korean J. Chem. Eng. 2011, 28, 2196-2201.

(11) Chuah, C. Y.; Yu, S.; Na, K.; Bae, T. H. J. Ind. Eng.

Chem. 2018, 62, 64-71.

(12) Chuah, C. Y.; Yang, Y.; Bae, T. H. Microporous

Mesoporous Mater. 2018, 272, 232-240.

(13) Hasell, T.; Miklitz, M.; Stephenson, A.; Little, M. A.; Chong, S. Y.; Clowes, R.; Chen, L.; Holden, D.; Tribello, G. A.; Jelfs, K. E.; et al. J. Am. Chem. Soc. 2o16, 138, 1653-1659.

(14) Sun, R.; Tai, C.-W.; Strømme, M.; Cheung, O. ACS Appl. Nano Mater. 2019, 2, 778-789.

(15) Yang, Y.; Goh, K.; Chuah, C. Y.; Karahan, H. E.; Birer, Ö.; Bae, T. H. Carbon 2019, 155, 56-64.

(16) Kim, M. B.; Lee, S. J.; Lee, C. Y.; Bae, Y. S. Microporous Mesoporous Mater. 2014, 190, 356-361.

(17) Kim, M. B.; Yoon, T. U.; Hong, D. Y.; Kim, S. Y.; Lee, S. J.; Kim, S. I.; Lee, S. K.; Chang, J. S.; Bae, Y. S. Chem. Eng. J. 2015, 276, 315-321.

(18) Kim, M. B.; Kim, K. M.; Kim, T. H.; Yoon, T. U.; Kim, E. J.; Kim, J. H.; Bae, Y. S. Chem. Eng. J. 2018, 339, 223-229.

(19) Kim, M. B.; Kim, T. H.; Yoon, T. U.; Kang, J. H.; Kim, J. H.; Bae, Y. S. J. Ind. Eng. Chem. 2020, 84, 179-184.

(20) Wang, T.; Chang, M.; Yan, T.; Ying, Y.; Yang, Q.; Liu,

D. Ind. Eng. Chem. Res. 2021, 6o, 5976-5983.

(21) Liao, Q.; Ke, C.; Huang, X.; Wang, D.; Han, Q.; Zhang, Y.; Zhang, Y.; Xi, K. Angew. Chemie Int. Ed. 2021, 6o, 1411-1416.

(22) Zheng, X.; Shen, Y.; Wang, S.; Huang, K.; Cao, D.

Chinese J. Chem. Eng. 2021. DOI: 10.1016/j.cjche.2021.03.010

(23) Dalapati, S.; Addicoat, M.; Jin, S.; Sakurai, T.; Gao, J.;

Xu, H.; Irle, S.; Seki, S.; Jiang, D. Nat. Commun. 2015, 6, 7786.

(24) Oschatz, M.; Antonietti, M. Energy Environ. Sci. 2018, 11, $57-70$.

(25) Gao, Q.; Li, X.; Ning, G. H.; Xu, H. Sen; Liu, C.; Tian, B.; Tang, W.; Loh, K. P. Chem. Mater. 2o18, 30, 1762-1768.

(26) Xiong, Y.; Liao, Q.; Huang, Z.; Huang, X.; Ke, C.; Zhu, H.; Dong, C.; Wang, H.; Xi, K.; Zhan, P.; et al. Adv. Mater. 2o2o, $32,1907242$.

(27) Hwang, J.; Joss, L.; Pini, R. Microporous Mesoporous Mater. 2019, 273, 107-121.

(28) Myers, A. L.; Prausnitz, J. M. AIChE J. 1965, 11, 121-127.

(29) Zeng, Y.; Zou, R.; Zhao, Y. Adv. Mater. 2016, 28, 28552873.

(30) Bhadra, M.; Kandambeth, S.; Sahoo, M. K.; Addicoat, M.; Balaraman, E.; Banerjee, R. J. Am. Chem. Soc. 2019, 141, 61526156.

(31) Liao, Q.; Wang, D.; Ke, C.; Zhang, Y.; Han, Q.; Zhang, Y.; Xi, K. Appl. Catal. B Environ. 2o21, 298, 120548.

(32) Li, Z.; Feng, X.; Zou, Y.; Zhang, Y.; Xia, H.; Liu, X.; Mu, Y. Chem. Commun. 2014, 50, 13825-13828.

(33) Uribe-romo, F. J.; Hunt, J. R.; Furukawa, H.; Klock, C.; O'Keeffe, M.; Yaghi, O. M. J. Am. Chem. Soc. 2oo9, 131, 4570-4571.

(34) Sick, T.; Rotter, J. M.; Reuter, S.; Kandambeth, S.; Bach, N. N.; Merz, J.; Clark, T.; Marder, T. B.; Bein, T.; Medina, D. D.; et al. J. Am. Chem. Soc. 2019, 141, 12570-12581.

(35) Liao, Q.; Ke, C.; Huang, X.; Zhang, G.; Zhang, Q.; Zhang, Z.; Zhang, Y.; Liu, Y.; Ning, F.; Xi, K. J. Mater. Chem. A 2019, 7, 18959-18970.

(36) Chen, Q.; Tang, J.; Fang Q. Chem. J. CHINESE Univ. 2018, 39, 2357-2362. 
（37） Ma, T.; Kapustin, E. A.; Yin, S. X.; Liang, L.; Zhou, Z.; Niu, J.; Li, L.-H.; Wang, Y.; Su, J.; Li, J.; et al. Science 2018, 361, 48-52.

(38) Fischbach, D. M.; Rhoades, G.; Espy, C.; Goldberg, F.; Smith, B. J. Chem. Commun. 2019, 55, 3594-3597.

(39) Builes, S.; Roussel, T.; Vega, L. F. Aiche J. 2011, 57, 962974.

(38) Kim, P. J.; You, Y. W.; Park, H.; Chang, J. S.; Bae, Y. S.; Lee, C. H.; Suh, J. K. Chem. Eng. J. 2015, 262, 683.
(39) Chuah, C. Y.; Goh, K.; Bae, T. H. J. Phys. Chem. C 2017, 121,6748

(40) Köppen, M.; Dhakshinamoorthy, A.; Inge, A. K.; Cheung, O.; Ångström, J.; Mayer, P.; Stock, N. Eur. J. Inorg. Chem. 2018, 2018, 3496. 
Table of Contents

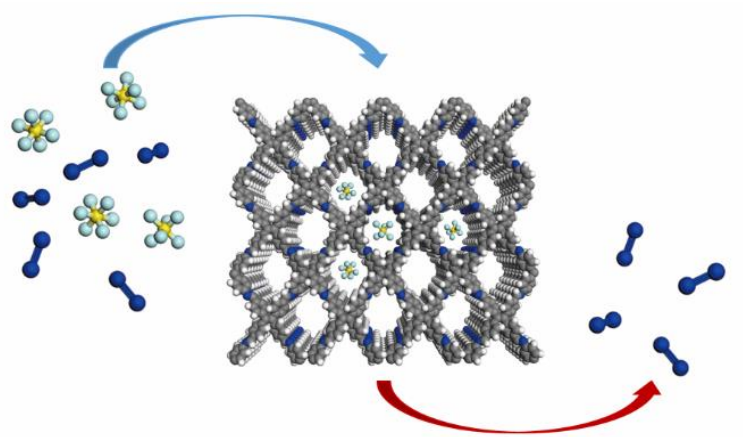

